\title{
Herpes simplex virus-2 infections in pregnant women from Durban, South Africa: prevalence, risk factors and co-infection with HIV-1
}

\author{
Nathlee S Abbai $^{a *}$ (D), Shanthie Govender ${ }^{a}$ (D) and Makandwe Nyirendab ${ }^{b}$ \\ ${ }^{a}$ School of Clinical Medicine, Nelson Mandela School of Medicine, University of KwaZulu-Natal, Durban, South Africa \\ ${ }^{b}$ South African Medical Research Council, HIV Prevention Research Unit, Durban, South Africa \\ *Corresponding author, Email: abbain@ukzn.ac.za
}

Currently there is a lack of data on herpes simplex virus-2 (HSV-2) and human immunodeficiency virus-1 (HIV-1) co-infections as well as risk factors for infection in antenatal women from South Africa. The present study attempts to fill this gap. This crosssectional study was conducted from April to August 2017 at the antenatal clinic of the King Edward VIII hospital in Durban, South Africa. In total 248 pregnant women participated in the study. Data on the women's demographics, sexual behaviour and clinical information were collected. HIV testing was conducted using a rapid test and the HerpeSelect 2 ELISA was used to test for HSV-2. The prevalence of HSV-2 and HIV- 1 was $71 \%$ and $50 \%$ and coinfection rate was $60 \%$. In adjusted analyses, women who were aged $\geq 35$ years (adjusted odds ratio [AOR]: $4.95, p=0.01$ ), experienced recent symptoms of genital itching/sores/warts (AOR 2.48, $p=0.05$ ) and were HIV-positive (AOR 3.64, $p<0.01$ ), were more likely to be infected with HSV-2. Older age (30-34 years old) (AOR 6.53, $p<0.01$ ) and having $\geq 4$ lifetime sex partners (AOR 4.59, $p=0.03$ ) were strongly associated with HSV-2/HIV-1 co-infections. The findings of this study call for continuous risk reduction counselling in this population.

Keywords: herpes simplex virus-2, HIV-1, pregnant women, risk factors

\section{Introduction}

According to the World Health Organization (WHO) approximately 536 million people aged $15-49$ years are infected with herpes simplex virus type 2 (HSV-2), the causative agent of genital herpes. ${ }^{1}$ In addition, an estimated 23.6 million people in this age group become newly infected with HSV-2 annually. The prevalence rates of HSV-2 infection are reported to be higher in women when compared with men, with the lowest prevalence rates being $13 \%$ among West European men and the highest prevalence rates being $70 \%$ among sub-Saharan African (SSA) women. ${ }^{1}$ In South Africa, the prevalence of HSV-2 infection is reported to be between $40 \%$ and $70 \%$ in women. ${ }^{2,3}$

In South Africa, HSV-2 seroprevalence among women of reproductive age is considerably higher than in the USA (30-70\% vs. $21 \%){ }^{4}$ HSV-2 incidence in southern Africa remains high throughout the reproductive years, at $8.8 / 100$ person-years among women 18-24 years of age and 5.3/100 person-years among women 35 years or older. This is higher than the USA, where estimated HSV-2 incidence is $2.25 / 100$ person-years among women $20-29$ years of age and $1.73 / 100$ person-years among women age $30-39$; of these, $1.0 \%$ of HSV-2 seronegative women seroconverted during pregnancy. This suggests that South African women may also be at risk of HSV-2 infection during pregnancy. ${ }^{4}$ In South Africa, routine screening for HSV2 infections during pregnancy is not the standard of care. As a result, infants that are exposed to the virus may be at increased risk of neonatal fatality. ${ }^{4}$

Previous studies have found a strong association between HSV-2 infection and HIV-1 infection. ${ }^{5}$ There are several reports suggesting that HSV-2 is a biological co-factor for HIV-1 acquisition. A meta-analysis performed by Freeman ${ }^{6}$ showed that the relative risk of HIV-1 acquisition associated with HSV-2 was 3.1 (95\% confidence interval $[\mathrm{Cl}] 1.7,5.6)$. It is suggested that
HSV-2 infection may contribute to $>50 \%$ new HIV infections among women in SSA. ${ }^{6}$ Some studies have reported high prevalence rates of these infections in general populations as well as high-risk populations. In a study by Abbai et al., ${ }^{3}$ the prevalence of HSV-2 and HIV-1 co-infection was reported to be $41 \%$ in South African women.

Some of the risk factors that have been associated with HSV-2 infections include older age, ${ }^{3,7,8}$ early menarche, ${ }^{9}$ low level of education, $^{10}$ and having a higher number of sex partners. ${ }^{3,10}$ However, most of the above-mentioned factors have been identified by assessing high-risk women who have participated in previous HIV prevention clinical trials. In addition, the majority of the studies that have identified risk factors for HSV-2 infection in pregnant women have been conducted outside South Africa. ${ }^{11-14}$ To this end, there are limited reports on the risk factors for HSV-2 infection in antenatal women from South Africa, in particular the province of KwaZulu-Natal. The present study aims to fill a gap in knowledge regarding the seroprevalence of HSV-2 infections and risk factors for infection in this target population.

In this study, a population of pregnant women were screened for the presence of HSV-2 antibodies. Through this study the risk factors associated with HSV-2 infections in pregnant women were identified. Additionally, the prevalence of HSV-2 and HIV-1 co-infection was investigated and risk factors associated with both infections were identified.

\section{Methods}

\section{Study setting and population}

This study was a cross-sectional study that was conducted from April to August 2017 at the antenatal clinic of the King Edward 
VIII hospital in Durban, KwaZulu-Natal, South Africa. King Edward VIII hospital is the second largest hospital in the Southern Hemisphere, providing regional and tertiary services to the whole of KwaZulu-Natal. A total of 248 women attending care and who met eligibility were enrolled in this study. During the study recruitment process, the refusal rate for participation was $20 \%$. On average the clinic attended to close to 80-100 patients daily. All women were 18 years and older and willing to complete a written informed consent form as well as provide a blood sample to be tested for HSV-2 infections. Women provided permission for the study staff to obtain information on their HIV status from their clinic records.

\section{Data and specimen collection}

At enrolment, a structured questionnaire was administered to collect data on the women's demographics (age, level of education, employment status, and marital status), sexual behaviour (condom use, cohabitation status, number of lifetime sex partners, age of sexual debut) and clinical information (trimester of pregnancy, HIV status, current symptoms of genital ulcers/ sores, history and treatment of STIs, method of contraception used prior to pregnancy).

Testing for HIV, which was part of the standard of care, was performed using the HIV 1/2/O Tri-line Human Immunodeficiency Virus Rapid Test Device test strip (ABON Biopharm Hangzhou Co., China). The testing was performed on fingerpick whole blood. Approximately $3.5 \mathrm{ml}$ of whole blood was collected by venepuncture by a professional nurse using a serum separator gel (SST) tube. The blood was transported to the University of KwaZulu-Natal, Nelson Mandela School of Medicine, School of Clinical Medicine Research Laboratory, for processing and testing. Serum was separated from the whole blood sample, transferred to a cryovial and stored at $-20^{\circ} \mathrm{C}$ until further testing.

\section{Laboratory testing}

Thawed serum samples were later tested using the HerpeSelect 2 ELISA IgG test kit (Quest Diagnostics, Madison, New Jersey, US) according to the manufacturer's recommendations with a high control cut-off of 3.5. The assay is a glycoprotein G-based type-specific ELISA technique that produces qualitative results. Controls that were provided with kits were included for all runs. The cut-off value used to determine a positive result was $>1.10$ index value; $0.9-1.10$ index values were considered equivocal and index values $<0.9$ were considered as negative results. All samples that produced equivocal index values were retested.

\section{Data analysis}

Associations between categorical variables were assessed using chi-square $\left(x^{2}\right)$ tests. Ordinary logistics regression models for the dichotomous outcome variable HSV-2 (positive vs. negative) were used to determine factors that contribute to prevalent HSV-2 infections in this pregnant cohort. In the case of the categorical variable of HSV-2 and HIV-1 co-infection, multinomial logistic regressions were used to identify factors that contributed to HSV-2/HIV-1 co-infection. This outcome variable had four categories: (1) negative for both HSV-2 and HIV-1; (2) positive for both HSV-2 and HIV-1, i.e. co-infected; (3) HSV2 positive and HIV-1 negative; and (4) HSV-2 negative and HIV-1 positive. The referent category in the multinomial models was being negative for both infections. Both ordinary and multinomial logistic regression models were adjusted for age (18-24, 25$29,30-34, \geq 35$ ), level of education (primary, secondary, tertiary), employed (yes/no), married (yes/no), behavioural factors (age at first sex, number of lifetime partners, partner having other partners, condom use), and clinical/biological factors (pregnancy trimester, contraception prior to pregnancy, genital ulcer/sore, STI symptoms, STI treatment). All statistical analyses were conducted using STATA 14.1. ${ }^{15}$ All $p$-values were considered significant at $<0.05$.

\section{Ethics}

Ethical and human participant research approvals was obtained from the Biomedical Research Ethics Committee, University of KwaZulu-Natal (BE525/16). All study-related material was approved before being used in this study.

\section{Results}

\section{Baseline characteristics of the study population stratified by HSV-2 status}

A total of $n=248$ pregnant women were enrolled in this study. Table 1 describes the study population according to HSV-2 status. The overall prevalence of HSV-2 in the study population was found to be $71 \%$. In this study, a higher proportion of women older than 35 years of age when compared with women who were 18-24 years of age tested HSV-2 positive ( $31.6 \%$ vs. $14.7 \%, p=0.01)$. Women who had obtained a secondary level of education when compared with women who only completed primary school $(70.6 \%$ vs. $5.1 \%, p=0.01)$ were also shown to be HSV-2 positive. HSV-2 seropositivity was higher in women who were unemployed compared with women who were employed $(60.5 \%$ vs. $39 \% .5, p=0.55)$ and a larger number of prevalent HSV-2 infections was found in women who were unmarried when compared with women who were married $(84.7 \%$ vs. $15.3 \%, p=0.01)$.

A higher number of HSV-2 infections was found in women who reported having a regular sex partner when compared with women that did not have a regular sex partner $(98.9 \%$ vs. $1.1 \%, p=0.34)$. In addition, a higher number of prevalent infections was observed in women who were not living with their current partner when compared with women who were cohabiting $(54.2 \%$ vs. $44.6 \%, p=0.51)$. A larger number of infections were found in women who had experienced first sex at ages $15-19$ years $(78.4 \%)$ versus women who had a sexual debut at an older age $(p=0.25)$. Having $2-4$ lifetime sex partners in comparison with women with one lifetime sex partner was associated with HSV-2 infections $(65 \%$ vs. $7.3 \%, p=0.001)$. Not knowing if their partner had other partners $(43.5 \%)$ was associated with prevalent HSV-2 infections in the study women ( $p=$ 0.78 ). A higher number of prevalent HSV-2 infections has been observed in women who reported using condoms "sometimes" when compared with women who "always" used condoms $(48.6 \%$ vs. $19.2 \%, p=0.01)$.

When considering clinical/biological factors and HSV-2 status, it was found that a larger number of women who were HSV-2 positive were in their second trimester of pregnancy when compared with women who had an early gestational age $(46.9 \%$ vs. $22 \%, p=0.67)$. There was a high prevalence of HSV-2 and HIV-1 co-infection in this study population $(60.5 \%, p<0.001)$. The majority of women who had prevalent HSV-2 infections showed symptoms of genital ulcers/sores $(66.7 \%, p=0.12)$ and had been previously treated for sexually transmitted infections in the past three months before enrolment $(57.6 \%, p=0.01)$. In addition, approximately $39 \%$ of the women who were HSV-2 positive had used an injectable form of contraception prior to becoming pregnant $(p=0.70)$. 
Table 1: Description of pregnant women enrolled in this study recruited from the antenatal clinic of the King Edward VIII hospital in Durban, South Africa

\begin{tabular}{|c|c|c|c|c|c|c|c|}
\hline \multirow{3}{*}{$\begin{array}{l}\text { Item } \\
\text { Sociodemographic factors }\end{array}$} & & & \multicolumn{5}{|c|}{ HSV-2 status } \\
\hline & \multicolumn{2}{|c|}{ Total } & \multicolumn{2}{|c|}{ Positive } & \multicolumn{2}{|c|}{ Negative } & \multirow[t]{2}{*}{$p$-value } \\
\hline & $n$ & $\%$ & $n$ & $\%$ & $n$ & $\%$ & \\
\hline Age: & & & & & & & 0.018 \\
\hline $18-24$ & 43 & $17.3 \%$ & 26 & $14.7 \%$ & 17 & $23.9 \%$ & \\
\hline $25-29$ & 75 & $30.2 \%$ & 47 & $26.6 \%$ & 28 & $39.4 \%$ & \\
\hline $30-34$ & 60 & $24.2 \%$ & 48 & $27.1 \%$ & 12 & $16.9 \%$ & \\
\hline$>35$ & 70 & $28.2 \%$ & 56 & $31.6 \%$ & 14 & $19.7 \%$ & \\
\hline Level of education: & & & & & & & 0.011 \\
\hline Primary & 12 & $4.8 \%$ & 9 & $5.1 \%$ & 3 & $4.2 \%$ & \\
\hline Secondary & 162 & $65.3 \%$ & 125 & $70.6 \%$ & 37 & $52.1 \%$ & \\
\hline Tertiary & 74 & $29.8 \%$ & 43 & $24.3 \%$ & 31 & $43.7 \%$ & \\
\hline Employed: & & & & & & & 0.551 \\
\hline Yes & 101 & $40.7 \%$ & 70 & $39.5 \%$ & 31 & $43.7 \%$ & \\
\hline No & 147 & $59.3 \%$ & 107 & $60.5 \%$ & 40 & $56.3 \%$ & \\
\hline Married: & & & & & & & 0.019 \\
\hline Yes & 47 & $19.0 \%$ & 27 & $15.3 \%$ & 20 & $28.2 \%$ & \\
\hline No & 201 & $81.0 \%$ & 150 & $84.7 \%$ & 51 & $71.8 \%$ & \\
\hline \multicolumn{8}{|l|}{ Behavioural factors } \\
\hline Has regular partner: & & & & & & & 0.340 \\
\hline Yes & 244 & $98.4 \%$ & 175 & $98.9 \%$ & 69 & $97.2 \%$ & \\
\hline No & 4 & $1.6 \%$ & 2 & $1.1 \%$ & 2 & $2.8 \%$ & \\
\hline Living with current partner: & & & & & & & 0.516 \\
\hline Yes & 107 & $43.1 \%$ & 79 & $44.6 \%$ & 28 & $39.4 \%$ & \\
\hline No & 137 & $55.2 \%$ & 96 & $54.2 \%$ & 41 & $57.7 \%$ & \\
\hline N/A & 4 & $1.6 \%$ & 2 & $1.1 \%$ & 2 & $2.8 \%$ & \\
\hline Age at first sex: & & & & & & & 0.253 \\
\hline$<15$ & 6 & $2.4 \%$ & 5 & $2.8 \%$ & 1 & $1.4 \%$ & \\
\hline 15-19 & 188 & $76.1 \%$ & 138 & $78.4 \%$ & 50 & $70.4 \%$ & \\
\hline $20-24$ & 41 & $16.6 \%$ & 27 & $15.3 \%$ & 14 & $19.7 \%$ & \\
\hline$>35$ & 12 & $4.9 \%$ & 6 & $3.4 \%$ & 6 & $8.5 \%$ & \\
\hline Lifetime number of sex partners: & & & & & & & 0.001 \\
\hline 1 & 30 & $12.1 \%$ & 13 & $7.3 \%$ & 17 & $23.9 \%$ & \\
\hline $2-4$ & 154 & $62.1 \%$ & 115 & $65.0 \%$ & 39 & $54.9 \%$ & \\
\hline$\geq 4$ & 64 & $25.8 \%$ & 49 & $27.7 \%$ & 15 & $21.1 \%$ & \\
\hline Partner has other partners: & & & & & & & 0.785 \\
\hline Yes & 66 & $26.6 \%$ & 49 & $27.7 \%$ & 17 & $23.9 \%$ & \\
\hline No & 74 & $29.8 \%$ & 51 & $28.8 \%$ & 23 & $32.4 \%$ & \\
\hline Don't know & 108 & $43.5 \%$ & 77 & $43.5 \%$ & 31 & $43.7 \%$ & \\
\hline Condom use: & & & & & & & 0.011 \\
\hline Never & 92 & $37.1 \%$ & 57 & $32.2 \%$ & 35 & $49.3 \%$ & \\
\hline Sometimes & 117 & $47.2 \%$ & 86 & $48.6 \%$ & 31 & $43.7 \%$ & \\
\hline Always & 39 & $15.7 \%$ & 34 & $19.2 \%$ & 5 & $7.0 \%$ & \\
\hline \multicolumn{8}{|l|}{ Clinical/biological } \\
\hline Trimester of pregnancy: & & & & & & & 0.671 \\
\hline $1 \mathrm{st}$ & 56 & $22.6 \%$ & 39 & $22.0 \%$ & 17 & $23.9 \%$ & \\
\hline 2nd & 119 & $48.0 \%$ & 83 & $46.9 \%$ & 36 & $50.7 \%$ & \\
\hline $3 r d$ & 73 & $29.4 \%$ & 55 & $31.1 \%$ & 18 & $25.4 \%$ & \\
\hline HIV status (enrolment): & & & & & & & $<0.001$ \\
\hline Negative & 122 & $49.2 \%$ & 69 & $39.0 \%$ & 53 & $74.6 \%$ & \\
\hline Positive & 124 & $50.0 \%$ & 107 & $60.5 \%$ & 17 & $23.9 \%$ & \\
\hline Refused & 2 & $0.8 \%$ & 1 & $0.6 \%$ & 1 & $1.4 \%$ & \\
\hline
\end{tabular}


Table 1: Continued.

\begin{tabular}{|c|c|c|c|c|c|c|c|}
\hline \multirow{3}{*}{\begin{tabular}{|l} 
Item \\
Contraception used before pregnancy:
\end{tabular}} & & & \multicolumn{5}{|c|}{ HSV-2 status } \\
\hline & \multicolumn{2}{|c|}{ Total } & \multicolumn{2}{|c|}{ Positive } & \multicolumn{2}{|c|}{ Negative } & \multirow{2}{*}{$\begin{array}{r}p \text {-value } \\
0.704\end{array}$} \\
\hline & & & & & & & \\
\hline None & 85 & $34.3 \%$ & 57 & $32.2 \%$ & 28 & $39.4 \%$ & \\
\hline Condom & 39 & $15.7 \%$ & 31 & $17.5 \%$ & 8 & $11.3 \%$ & \\
\hline Oral & 16 & $6.5 \%$ & 11 & $6.2 \%$ & 5 & $7.0 \%$ & \\
\hline Injection & 96 & $38.7 \%$ & 69 & $39.0 \%$ & 27 & $38.0 \%$ & \\
\hline Implant & 12 & $4.8 \%$ & 9 & $5.1 \%$ & 3 & $4.2 \%$ & \\
\hline Current symptoms of genital ulcers/sores: & & & & & & & 0.126 \\
\hline Yes & 158 & $63.7 \%$ & 118 & $66.7 \%$ & 40 & $56.3 \%$ & \\
\hline No & 90 & $36.3 \%$ & 59 & $33.3 \%$ & 31 & $43.7 \%$ & \\
\hline Treated for STI: & & & & & & & 0.010 \\
\hline Yes & 130 & $52.4 \%$ & 102 & $57.6 \%$ & 28 & $39.4 \%$ & \\
\hline No & 118 & $47.6 \%$ & 75 & $42.4 \%$ & 43 & $60.6 \%$ & \\
\hline STI symptoms: & & & & & & & 0.079 \\
\hline None & 26 & $10.5 \%$ & 18 & $10.2 \%$ & 8 & $11.3 \%$ & \\
\hline Abnormal vaginal discharge (AVD)/foul-smelling odour & 63 & $25.4 \%$ & 52 & $29.4 \%$ & 11 & $15.5 \%$ & \\
\hline Genital itching/warts/sores & 23 & $9.3 \%$ & 18 & $10.2 \%$ & 5 & $7.0 \%$ & \\
\hline Multiple (AVD \& genital) & 136 & $54.8 \%$ & 89 & $50.3 \%$ & 47 & $66.2 \%$ & \\
\hline
\end{tabular}

\section{Factors associated with HSV-2 infections}

In this study population, pregnant women who were $\geq 35$ years were more likely to be infected with HSV-2 (adjusted odds ratio [AOR] 4.95, 95\% Cl 1.39-17.5, $p=0.01$ ). HIV status was strongly associated with HSV-2 infections. Women who were HIV-positive were three times more likely to be infected with HSV-2 (AOR 3.64, $95 \% \mathrm{Cl} 1.64-8.05, p=0.001$ ). In addition, women who had experienced past symptoms of genital itching/sores/warts were more likely to be HSV-2 seropositive (AOR 2.48, 95\% Cl 0.99-6.14, $p=$ 0.05 ). Women who had four and more lifetime sex partners were most likely to be HSV-2 positive when compared with women with just one partner. Although there was a significant association between lifetime number of sex partners and HSV-2 status in the unadjusted analysis (AOR 4.20, 95\% Cl 1.69-10.4, $p$ $<0.001)$, this association was not maintained in the adjusted analysis (AOR 1.68, 95\% Cl 0.51-5.43, $p=0.39$ ) (Table 2).

\section{Factors associated with HSV-2 and HIV-1 co-infections}

According to the analysis, age and number of lifetime sex partners were strongly associated with HSV-2 and HIV-1 co-infections (Table 3). Women who were between the ages of 30 and 34 years of age were more than six times more likely (AOR $6.53,95 \% \mathrm{Cl} 1.53-27.7, p=0.01$ ) to be infected with HSV-2 and HIV-1 when compared with women who were 18-24 years of age. Having four and more lifetime sex partners put the women at higher risk of being infected with HSV-2 and HIV-1 (AOR 4.59, 95\% Cl 1.14-19.1, $p=0.03$ ) when compared with women who reported having fewer sex partners. Recent symptoms (past three months) of genital itching, genital warts and genital sores also increased the women's risk of being coinfected with both viruses (AOR 4.43, 95\% Cl 0.98-19.9, $p=0.05$ ).

\section{Discussion}

In this study of women attending antenatal care at the King Edward VIII hospital in Durban, South Africa, the overall prevalence of HSV-2 infections was reported to be $71 \%$. The prevalence estimates reported in this study was found to be higher than recent reports from pregnant women from countries outside Africa, i.e. Brazil (21\%), ${ }^{11}$ Haiti $(31 \%),{ }^{12}$ as well as within the African continent (Ethiopia, 32\%; ${ }^{13}$ Uganda $53 \%{ }^{14}$ ). A recent study from Soweto in South Africa reported a HSV-2 seroprevalence of $59 \%$ in pregnant women. ${ }^{4}$ Our study shows that prevalent HSV-2 infection is high among pregnant women in South Africa when compared with other parts of the globe. In addition, the prevalence estimates reported in this study are higher than the global prevalence (15\%) of HSV-2 in women. ${ }^{16}$

The number of HSV-2 infections was found to be higher in HIVpositive pregnant $(60 \%)$ women when compared with women who were HIV uninfected (39\%). In this study, it was shown that HIV-positive women were three times more likely to be HSV-infected than HIV-uninfected women. This association was maintained even after adjusting for confounding variables $(p=0.001)$. Similar observations were reported for studies conducted by Aebi-Popp et al. ${ }^{17}$ and Domercant et al. ${ }^{12}$ Infection with HIV has been implicated in enhancing the genital shedding of HSV-2, despite the absence of clinical lesions. ${ }^{3}$ These findings therefore advocate the need for evidenced-based interventions that are directed towards preventing HSV-2 infections among populations that reside in settings that have a generalised HIV epidemic. $^{12}$

In this study, an increase in HSV-2 prevalence was observed with increasing age. The highest number of HSV-2 infections was reported for women who were $\geq 35$ years old. These older women were four times more likely to be HSV-2 positive when compared with women who were 18-24 years of age ( $p=$ 0.014). This finding is consistent with recently published studies in which older age was associated with HSV-2 infection in pregnant and non-pregnant populations. ${ }^{3,11,12,17-19}$ According to Perti et al., ${ }^{4}$ the increasing number of prevalent HSV-2 infections with increasing age is the result of the longest time of herpes exposure. In addition, age was also shown to be strongly associated with HSV-2 and HIV-1 co-infections in this study - women aged 30-34 years were at increased risk for 
Table 2: Unadjusted and adjusted factors associated with prevalent HSV-2 infections in the pregnant women enrolled in this study from the King Edward VIII hospital

\begin{tabular}{|c|c|c|c|c|c|c|c|c|}
\hline \multirow[b]{2}{*}{ HSV-2 } & \multicolumn{4}{|c|}{ Unadjusted } & \multicolumn{4}{|c|}{ Adjusted } \\
\hline & OR & {$[95 \%$} & $\mathrm{Cl}]$ & $p$-value & OR & {$[95 \%$} & $\mathrm{Cl}]$ & $p$-value \\
\hline \multicolumn{9}{|l|}{ Age group: } \\
\hline $18-24$ & 1.00 & & & & 1.00 & & & \\
\hline $25-29$ & 1.09753 & 0.5083 & 2.3700 & 0.813 & 1.13 & 0.4468 & 2.8762 & 0.792 \\
\hline $30-34$ & 2.61538 & 1.0851 & 6.3035 & 0.032 & 3.53 & 1.0546 & 11.8139 & 0.041 \\
\hline$>35$ & 2.61538 & 1.1217 & 6.0982 & 0.026 & 4.95 & 1.3910 & 17.5924 & 0.014 \\
\hline \multicolumn{9}{|l|}{ Employed: } \\
\hline No & 1.00 & & & & 1.00 & & & \\
\hline Yes & 0.84 & 0.4834 & 1.4740 & 0.551 & 0.67 & 0.3269 & 1.3728 & 0.274 \\
\hline \multicolumn{9}{|l|}{ Married: } \\
\hline No & 1.00 & & & & 1.00 & & & \\
\hline Yes & 0.46 & 0.2373 & 0.8879 & 0.021 & 0.25 & 0.0859 & 0.7016 & 0.009 \\
\hline \multicolumn{9}{|l|}{ Cohabiting: } \\
\hline Yes & 1.00 & & & & 1.00 & & & \\
\hline No & 1.20 & 0.6847 & 2.1207 & 0.518 & 1.36 & 0.5488 & 3.3792 & 0.505 \\
\hline$N / A$ & 0.43 & 0.0582 & 3.1362 & 0.403 & 0.77 & 0.0736 & 8.1440 & 0.831 \\
\hline \multicolumn{9}{|l|}{ Age at first sex: } \\
\hline$<15$ & 1.00 & & & & 1.00 & & & \\
\hline $15-19$ & 0.55 & 0.0629 & 4.8407 & 0.592 & 1.32 & 0.1198 & 14.4993 & 0.821 \\
\hline $20-24$ & 0.39 & 0.0410 & 3.6303 & 0.405 & 0.97 & 0.0793 & 11.9057 & 0.982 \\
\hline$>35$ & 0.20 & 0.0177 & 2.2649 & 0.194 & 0.29 & 0.0192 & 4.4888 & 0.379 \\
\hline \multicolumn{9}{|l|}{ Lifetime number of sex partners: } \\
\hline 1 & 1.00 & & & & 1.00 & & & \\
\hline $2-4$ & 3.86 & 1.7183 & 8.6533 & 0.001 & 2.18 & 0.7931 & 5.9757 & 0.131 \\
\hline$>4$ & 4.27 & 1.6936 & 10.7749 & 0.002 & 1.68 & 0.5169 & 5.4319 & 0.39 \\
\hline \multicolumn{9}{|l|}{ Partner has other partners: } \\
\hline Yes & 1.00 & & & & 1.00 & & & \\
\hline No & 1.30 & 0.6206 & 2.7228 & 0.487 & 1.37 & 0.5411 & 3.4818 & 0.505 \\
\hline Don't know & 1.12 & 0.5877 & 2.1353 & 0.73 & 1.09 & 0.4759 & 2.5020 & 0.837 \\
\hline \multicolumn{9}{|l|}{ Condom use: } \\
\hline Always & 1.00 & & & & 1.00 & & & \\
\hline Never & 0.24 & 0.0856 & 0.6700 & 0.006 & 0.64 & 0.1799 & 2.3113 & 0.501 \\
\hline Sometimes & 0.41 & 0.1464 & 1.1366 & 0.086 & 1.05 & 0.3102 & 3.5439 & 0.939 \\
\hline \multicolumn{9}{|l|}{ Contraception used before pregnancy: } \\
\hline None & 1.00 & & & & 1.00 & & & \\
\hline Condoms & 1.90 & 0.7745 & 4.6785 & 0.161 & 1.30 & 0.4420 & 3.8022 & 0.636 \\
\hline Oral & 1.08 & 0.3422 & 3.4125 & 0.895 & 1.06 & 0.2390 & 4.6993 & 0.939 \\
\hline Injections & 1.26 & 0.6656 & 2.3676 & 0.482 & 0.84 & 0.3814 & 1.8579 & 0.67 \\
\hline Implant/loop & 1.47 & 0.3697 & 5.8737 & 0.583 & 0.39 & 0.0782 & 1.9036 & 0.242 \\
\hline \multicolumn{9}{|l|}{ STI symptoms: } \\
\hline None & 1.00 & & & & 1.00 & & & \\
\hline Abnormal vaginal discharge/foul-smelling odour & 1.19 & 0.4808 & 2.9363 & 0.709 & 0.95 & 0.3200 & 2.8164 & 0.925 \\
\hline Genital & 2.50 & 1.1908 & 5.2337 & 0.015 & 2.48 & 0.9979 & 6.1437 & 0.051 \\
\hline Multiple & 1.90 & 0.6640 & 5.4434 & 0.231 & 1.72 & 0.4833 & 6.1481 & 0.401 \\
\hline \multicolumn{9}{|l|}{ Had genital ulcer: } \\
\hline No & 1.00 & & & & 1.00 & & & \\
\hline Yes & 1.55 & 0.8822 & 2.7233 & 0.127 & 0.88 & 0.4129 & 1.8911 & 0.75 \\
\hline \multicolumn{9}{|l|}{ HIV: } \\
\hline \multicolumn{9}{|l|}{ Negative } \\
\hline Positive & 4.83 & 2.5890 & 9.0279 & $<0.001$ & 3.64 & 1.6468 & 8.0595 & 0.001 \\
\hline Refused & 0.77 & 0.0470 & 12.5663 & 0.853 & 0.79 & 0.0393 & 16.0769 & 0.881 \\
\hline
\end{tabular}


Table 3: Risk factors for HSV-2 and HIV-1 co-infections in the pregnant women enrolled in this study

\begin{tabular}{|c|c|c|c|c|}
\hline Variable & AOR & {$[95 \%$} & $\mathrm{Cl}]$ & $\begin{array}{c}p- \\
\text { value }\end{array}$ \\
\hline \multicolumn{5}{|l|}{ Age group } \\
\hline $18-24$ & 1.00 & & & \\
\hline $25-29$ & 1.74 & 0.5018 & 6.0122 & 0.383 \\
\hline $30-34$ & 6.53 & 1.5372 & 27.7573 & 0.011 \\
\hline$>35$ & 5.00 & 1.1198 & 22.2837 & 0.035 \\
\hline Unemployed & 0.44 & 0.1847 & 1.0585 & 0.067 \\
\hline Not married & 0.17 & 0.0462 & 0.6191 & 0.007 \\
\hline \multicolumn{5}{|l|}{ Cohabiting with partner: } \\
\hline Yes & 1.00 & & & \\
\hline No & 2.78 & 0.9237 & 8.3516 & 0.069 \\
\hline Refuses to provide data & 3.43 & 0.1233 & 95.6384 & 0.467 \\
\hline \multicolumn{5}{|l|}{$\begin{array}{l}\text { Lifetime number of sex } \\
\text { partners: }\end{array}$} \\
\hline 1 & 1.00 & & & \\
\hline $2-4$ & 2.89 & 0.8174 & 10.2294 & 0.100 \\
\hline$>4$ & 4.59 & 1.1236 & 18.7862 & 0.034 \\
\hline \multicolumn{5}{|l|}{ Partner has other partners: } \\
\hline Yes & 1.00 & & & \\
\hline No & 0.85 & 0.2908 & 2.4994 & 0.771 \\
\hline Don't know & 0.72 & 0.2602 & 2.0036 & 0.532 \\
\hline \multicolumn{5}{|l|}{ Condom use: } \\
\hline Always & 1.00 & & & \\
\hline Never & 0.02 & 0.0020 & 0.1647 & $<0.001$ \\
\hline Sometimes & 0.09 & 0.0104 & 0.8035 & 0.031 \\
\hline \multicolumn{5}{|l|}{$\begin{array}{l}\text { Contraception used before } \\
\text { pregnancy: }\end{array}$} \\
\hline None & 1.00 & & & \\
\hline Condoms & 0.98 & 0.2571 & 3.7251 & 0.975 \\
\hline Oral & 1.77 & 0.2409 & 12.9415 & 0.576 \\
\hline Injections & 1.77 & 0.6769 & 4.6501 & 0.244 \\
\hline Implant/loop & 3.15 & 0.2510 & 39.4379 & 0.374 \\
\hline \multicolumn{5}{|l|}{$\begin{array}{l}\text { Symptoms of STIs/RTIs } \\
\text { (past } 3 \text { months): }\end{array}$} \\
\hline None & 1.00 & & & \\
\hline $\begin{array}{l}\text { Abnormal vaginal } \\
\text { discharge (AVD)/odour }\end{array}$ & 0.66 & 0.1811 & 2.3822 & 0.522 \\
\hline Genital itching/sores/warts & 2.77 & 0.9002 & 8.5348 & 0.076 \\
\hline $\begin{array}{l}\text { Multiple (AVD and genital } \\
\text { itching/sores/warts) }\end{array}$ & 1.91 & 0.3582 & 10.1579 & 0.449 \\
\hline \multicolumn{5}{|l|}{$\begin{array}{l}\text { Current symptoms of } \\
\text { genital ulcers/sores: }\end{array}$} \\
\hline No & 1.00 & & & \\
\hline Yes & 1.17 & 0.4485 & 3.0343 & 0.752 \\
\hline
\end{tabular}

HSV-2 and HIV-1 co-infections. Other risk factors identified for the women who were co-infected included having a greater number of lifetime sex partners and recent symptoms of genital itching, genital warts and genital sores. This calls for continuous risk-reduction counselling in this population.

The limitations of our study include, first, that we conducted the study at a single antenatal setting in KwaZulu-Natal, therefore the data are not representative of all pregnant women in KwaZuluNatal. Despite this limitation the data obtained in this study add to the growing body of evidence on HSV-2 infections and HSV2 and HIV-1 co-infection during pregnancy, an area of research in which data is lacking in our setting. Since the present study had a cross-sectional design we were unable to establish which infection came first, HIV-1 or HSV-2. Additionally, this study provides a basis for the development of future research that may be directed towards looking at the epidemiology of HSV-2 during pregnancy and associated birth and neonatal outcomes. Lastly, in this study we used the Focus HerpeSelect ${ }^{\mathrm{TM}}$ ELISA IgG to diagnose HSV-2. This test has been shown to have a reduced sensitivity and specificity in populations of high HIV prevalence, which could have affected interpretation of the results. To circumvent this, we used a cut-off that has been known to provide an estimated specificity of $>90 \%$ in African populations. In addition, we used the second-generation Focus HerpeSelect ${ }^{\mathrm{TM}}$ ELISA IgG, which is more specific than the first-generation test, therefore we did not need to confirm our findings with a Western Blot.

\section{Conclusion}

In this study of pregnant women, a very high prevalence for HSV-2 as well as HSV-2/HIV-1 co-infection was reported. According to the South African National Strategic Plan (NSP) for HIV, STIs and TB (2017-2022), ${ }^{20}$ one of the most neglected areas of the NSP has been the diagnosis and treatment of STIs. The proposed study has aligned with the NSP, since this study focused on screening for an STI in pregnant women as well as identified risk factors for infection. The high HSV-2 seroprevalence reported and risk factors identified in this study call for an improvement in current risk-reduction methods in our local setting. We need to adopt a funnel approach when it comes to community awareness on STIs, and we need to start educating the entire community first and then move down to individual high-risk groups because we are residing in a setting with a high HSV-2 prevalence and generalised HIV-1 epidemic.

Acknowledgements - The authors gratefully acknowledge the women from the King Edward VIII hospital antenatal clinic who participated in this study. They thank Ms Lungile Mbambo for recruiting the study population and collecting the data.

Disclosure statement - No potential conflict of interest was reported by the authors.

Funding - This study was supported by the National Research Foundation and the University of KwaZulu-Natal (Durban).

\section{ORCID}

Nathlee S Abbai (D) http://orcid.org/0000-0003-2392-0574

Shanthie Govender (D) http://orcid.org/0000-0002-8003-0060 Makandwe Nyirenda (D) http://orcid.org/0000-0002-1839-877X

\section{References}

1. Looker KJ, Garnett GP, Schmid GP. An estimate of the global prevalence and incidence of herpes simplex virus type 2 infection. Bull World Health Organ. 2008;86:805-12.

2. Kenyon C, Colebunders R, Buve A, et al. P3.065 partner-concurrency associated with HSV-2 infection in young South Africans. Sex Transm Infect. 2013;89:A168.3-A168.

3. Abbai NS, Wand H, Ramjee G. Socio-demographic and behavioural characteristics associated with HSV-2 sero-prevalence in high risk women in KwaZulu-Natal. BMC Res Notes. 2015;8:1.

4. Perti T, Nyati M, Gray G, et al. Frequent genital HSV-2 shedding among women during labor in Soweto, South Africa. Infect Dis Obstet Gynecol. 2014;2014:1-8. 
5. Glynn JR, Biraro S, Weiss HA. Herpes simplex virus type 2: a key role in HIV incidence. AIDS. 2009;23:1595-8.

6. Freeman EE, Weiss HA, Glynn JR, et al. Herpes simplex virus 2 infection increases HIV acquisition in men and women: systematic review and meta-analysis of longitudinal studies. AIDS. 2006;20:73-83.

7. Kenyon C, Colebunders R, Hens N. Determinants of generalized herpes simplex virus-2 epidemics: the role of sexual partner concurrency. IJSA. 2013;24:375-82.

8. Kirakoya-Samadoulougou F, Nagot N, Defer M-C, et al. Epidemiology of herpes simplex virus type 2 infection in rural and urban Burkina Faso. Sex Transm Dis. 2011;38:117-23.

9. Glynn JR, Kayuni N, Gondwe L, et al. Earlier menarche is associated with a higher prevalence of herpes simplex type-2 (HSV-2) in young women in rural Malawi. Elife. 2014;3:e01604.

10. Kapiga SH, Ewings FM, Ao T, et al. The epidemiology of HIV and HSV-2 infections among women participating in microbicide and vaccine feasibility studies in Northern Tanzania. PLoS One. 2013;8:e68825.

11. Lima L, Padalecki G, Castro C, et al. Seroprevalence of human herpesvirus type 2 in a reference center for pregnant women in Rio de Janeiro, Brazil. Virus Rev Res. 2017;22:20-21.

12. Domercant JW, Louis FJ, Hulland E, et al. Seroprevalence of herpes simplex virus type-2 (HSV-2) among pregnant women who participated in a national HIV surveillance activity in Haiti. BMC Infect Dis. 2017;17:577.

13. Anjulo AA, Abebe T, Hailemichael F, et al. Seroprevalence and risk factors of herpes simplex virus- 2 among pregnant women attending antenatal care at health facilities in wolaita zone, Ethiopia. Virol J. 2016;13:43.

14. Nakubulwa S, Kaye DK, Bwanga F, et al. Incidence and risk factors for herpes simplex virus type 2 seroconversion among pregnant women in Uganda: a prospective study. J Infect Dev Ctries. 2016;10:1108-15.

15. StataCorp. Stata: release 14. statistical software. 13.1 ed. College Station, TX: StataCorp LP; 2014.

16. Looker KJ, Magaret AS, Turner KM, et al. Global estimates of prevalent and incident herpes simplex virus type 2 infections in 2012. PloS One. 2015;10:e114989.

17. Aebi-Popp K, Bailey H, Malyuta R, et al. High prevalence of herpes simplex virus (HSV)-type 2 co-infection among HIV-positive women in Ukraine, but no increased HIV mother-to-child transmission risk. BMC Pregnancy Childbirth. 2016;16:94.

18. Abbai NS, Nyirenda M, Naidoo S, et al. Prevalent herpes simplex virus2 increases the risk of incident bacterial vaginosis in women from South Africa. AIDS Behav. 2018;22:2172-80.

19. Daniels B, Wand $H$, Ramjee G. Prevalence of herpes simplex virus 2 (HSV-2) infection and associated risk factors in a cohort of HIV negative women in Durban, South Africa. BMC Res Notes. 2016;9:510.

20. Government of South Africa. South African national strategic plan on HIV TaS-Wdfchnsoz.

Received: 7-12-2017 Accepted: 1-10-2018 